\title{
Association of subclinical hypercortisolism with type 2 diabetes mellitus: a case-control study in hospitalized patients
}

Iacopo Chiodini $^{1}$, Massimo Torlontano ${ }^{2}$, Alfredo Scillitani ${ }^{2}$, Maura Arosio ${ }^{1,3}$, Simonetta Bacci ${ }^{2}$, Sergio Di Lembo $^{1}$, Paolo Epaminonda ${ }^{1}$, Giovanni Augello ${ }^{2}$, Riccardo Enrini ${ }^{4}$, Bruno Ambrosi ${ }^{4}$, Guido Adda ${ }^{1}$ and Vincenzo Trischitta $^{2,5}$

${ }^{1}$ Unit of Endocrinology 'San Giuseppe-Fatebenefratelli' Hospital, A.Fa.R. Milano, via San Vittore 1220123 Milan, Italy, ${ }^{2}$ Unit of Endocrinology, Scientific Institute 'Casa Sollievo della Sofferenza', $S$ Giovanni Rotondo, Italy, ${ }^{3}$ Institute of Endocrine Sciences, University of Milan, Fondazione Policlinico IRCCS, Milan, Italy, ${ }^{4}$ Unit of Endocrinology, Department of Medical and Surgical Sciences, University of Milan, 'Policlinico San Donato' Institute, San Donato Milanese, Milan, Italy and 'Department of Clinical Sciences, 'La Sapienza' University, Rome, Italy

(Correspondence should be addressed to I Chiodini; Email: ichiodini@katamail.com)

\begin{abstract}
Objective: Subclinical hypercortisolism (SH) may play a role in several metabolic disorders, including diabetes. No data are available on the relative prevalence of SH in type 2 diabetes (T2D). In order to compare the prevalence of SH in T2D and matched non-diabetic control individuals, we performed a case-controlled, multicenter, 12-month study, enrolling 294 consecutive T2D inpatients (1.7\% dropped out the study) with no evidence of clinical hypercortisolism and 189 consecutive age- and body mass index-matched non-diabetic inpatients (none of whom dropped out).

Design and methods: Ascertained SH (ASH) was diagnosed in individuals (i) with plasma cortisol after $1 \mathrm{mg}$ overnight dexamethasone suppression $>1.8 \mu \mathrm{g} / \mathrm{dl}(50 \mathrm{nmol} / \mathrm{l})$, (ii) with more than one of the following: (a) urinary free cortisol $>60.0 \mu \mathrm{g} / 24 \mathrm{~h}(165.6 \mathrm{nmol} / 24 \mathrm{~h})$, (b) plasma ACTH $<10.0 \mathrm{pg} / \mathrm{ml}(2.2 \mathrm{pmol} / \mathrm{l})$ or (c) plasma cortisol $>7.5 \mu \mathrm{g} / \mathrm{dl}(207 \mathrm{nmol} / \mathrm{l})$ at $24: 00 \mathrm{~h}$ or $>1.4 \mu \mathrm{g} / \mathrm{dl}$ $(38.6 \mathrm{nmol} / \mathrm{l})$ after dexamethasone-CRH (serum cortisol after corticotrophin-releasing hormone stimulus during dexamethasone administration) test, and (iii) in whom the source of glucocorticoid excess was suggested by imaging and by additional biochemical tests (for ACTH-dependent ASH). Results: Prevalence of ASH was higher in diabetic individuals than in controls (9.4 versus 2.1\%; adjusted odds ratio, 4.8; $95 \%$ confidence interval, $1.6-14.1 ; P=0.004)$. In our population the proportion of T2D which is statistically attributable to ASH was approx. 7\%. Among diabetic patients, the presence of severe diabetes (as defined by the coexistence of hypertension, dyslipidaemia and insulin treatment) was significantly associated with $\mathrm{SH}$ (adjusted odds ratio, 3.8; 95\% confidence interval, $1.4-10.2 ; P=0.017)$.
\end{abstract}

Conclusions: In hospitalized patients, SH is associated with T2D.

European Journal of Endocrinology 153 837-844

\section{Introduction}

Type 2 diabetes (T2D) is a common disorder that may be sustained by several endocrine diseases (1). Overt endogenous glucocorticoid excess (Cushing's syndrome) is a well-recognized cause of hyperglycaemia (2); however, due to the low prevalence (1/500 000) in the general population (3), its epidemiological role on diabetes development is trivial.

Subclinical hypercortisolism (SH) is a recently defined entity, characterized by impaired adrenocorticotrophic hormone (ACTH)/cortisol homeostasis without classical signs or symptoms of Cushing's syndrome (3). SH is definitely more common than Cushing's syndrome, with an estimated prevalence of about 8/10 000 in the general population; in fact, this prevalence is likely to be underestimated because of the lack of specific clinical picture in SH patients $(3-8)$. Worth noting, preliminary reports have suggested that these patients are at high risk of T2D (9-13) and, most importantly, those who are diabetic are expected to experience clinical improvement after SH removal (14).

Recently, a high prevalence of $\mathrm{SH}$ has been suggested in patients with T2D with poor metabolic control (15). Unfortunately, in this previous study no comparison with a control non-diabetic population was available, making the significance of this observation uncertain. To address the issue of $\mathrm{SH}$ prevalence in T2D as compared with that in non-diabetic individuals a multicenter, case-controlled study, comprising 294 T2D patients and 189 age- and body mass index (BMI)-matched non-diabetic controls, was carried out. 


\section{Subjects and methods}

\section{Subjects}

Subjects were recruited from January 2003 to January 2004 at San Giuseppe-Fatebenefratelli Hospital in Milan, Italy, Istituto Policlinico San Donato in San Donato Milanese in Milan and Casa Sollievo della Sofferenza Scientific Institute in San Giovanni Rotondo, Foggia, Italy.

Given the reported prevalence of SH in diabetics (15) and in the general population (3) we estimated that a sample of 152 patients and 152 controls was needed to reach a statistical significance of 0.05 with $80 \%$ power. Based on the rate of diabetic and non-diabetic subjects admitted to our institutions who were potentially eligible for this study, a 1-year recruitment time was planned for collecting the study sample. The study was carried out on 294 consecutive T2D inpatients referring to our units for poor metabolic control. Selection criteria were as follows: age at diagnosis $>30$ years, BMI $\geq 19$ and $<50 \mathrm{~kg} / \mathrm{m}^{2}$, no need for insulin therapy in the first 2 years of disease, no history of ketoacidosis, an absence of signs or symptoms of hypercortisolism (includin, moon face, striae rubrae, hypertricosis, skin atrophy and buffalo hump) and/or hyperandrogenism, chronic renal failure, acute illnesses, unawareness hypoglycaemia, alteration of sleep-wake cycle, depression, alcoholism, past or present glucocorticoid therapy or intake of drugs known to interfere with the pituitary-adrenal axis. One hundred and eighty-nine consecutive age- and BMI-matched non-diabetic (fasting blood glucose $<110 \mathrm{mg} / \mathrm{dl}-<6.05 \mathrm{mmol} / \mathrm{l}$ and a normal oral glucose tolerance test (1)) inpatients were selected as controls according to the above-mentioned selection criteria. The reasons for hospital admission of control subjects were severe obesity and multinodular goitre with normal thyroid function.

Subjects with a systolic blood pressure $>130 \mathrm{mmHg}$ and/or a diastolic blood pressure $>80 \mathrm{mmHg}$ and/or who were on antihypertensive treatment were defined as hypertensive. Dyslipidaemia was defined as low-density lipoprotein-cholesterol $>3.4 \mathrm{mmol} / \mathrm{l}$ or triglycerides $>2.3 \mathrm{nmol} / \mathrm{l}$ or high-density lipoproteincholesterol $<0.9 \mathrm{mmol} / \mathrm{l}$ in males and $<1.2 \mathrm{mmol} / \mathrm{l}$ in females, or if antidyslipidemic treatment was given. In diabetic patients glycated haemoglobin $\left(\mathrm{HbA}_{1 \mathrm{C}}\right)$ levels were also obtained.

The design of the study is summarized in Fig. 1. In all subjects serum cortisol levels at 08:00 h after $1 \mathrm{mg}$ overnight dexamethasone-suppression test (F-Dex) was measured. In subjects with serum cortisol levels above $1.8 \mu \mathrm{g} / \mathrm{dl}(50.0 \mathrm{nmol} / \mathrm{l}) \mathrm{F}-\mathrm{Dex}$ was repeated. In those in whom incomplete suppression was confirmed, 24-h urinary free cortisol (UFC), plasma ACTH and plasma cortisol at midnight (F24) and/or cortisol after dexamethasone-CRH test (serum cortisol after corticotrophin-releasing hormone (CRH) stimulus during dexamethasone administration; Dex-CRH) were measured. It has been recently proposed that subjects from the general population with incomplete F-Dex suppression have to be considered as affected by SH if at least one of the following criteria is present: (a) UFC levels higher than $60 \mu \mathrm{g} / 24 \mathrm{~h}, \quad(165.6 \mathrm{nmol} / 24 \mathrm{~h})$, (b) plasma ACTH lower than $10 \mathrm{pg} / \mathrm{ml}(2.2 \mathrm{pmol} / \mathrm{l})$ and (c) F24 higher than $7.5 \mu \mathrm{g} / \mathrm{dl}(207 \mathrm{nmol} / \mathrm{l})$ and/or Dex$\mathrm{CRH}$ higher than $1.4 \mu \mathrm{g} / \mathrm{dl}(38.6 \mathrm{nmol} / \mathrm{l})(3,9,16-$ 18). No data are available about the applicability of these criteria to the diabetic population, which might, in fact, show altered pituitary-adrenal axis secondary to hyperglycaemia (19-21). Therefore, in our study subjects with the above-mentioned criteria were prudentially considered as possibly affected by $\mathrm{SH}$ (suspected $\mathrm{SH}$ ), whereas a definitive diagnosis of $\mathrm{SH}$ (ascertained $\mathrm{SH}$; ASH) was limited to those patients in whom the source of SH was identified. To this purpose, subjects with ACTH levels lower than $10 \mathrm{pg} / \mathrm{ml}(2.2 \mathrm{pmol} / \mathrm{l})$ underwent abdominal computed tomography (CT). Patients with ACTH levels higher than $10 \mathrm{pg} / \mathrm{ml}$ (2.2 pmol/l) underwent abdominal CT, nuclear magnetic resonance (NMR) of the pituitary region and biochemical tests (cortisol after $8 \mathrm{mg}$ overnight dexamethasone suppression, ACTH and cortisol after $\mathrm{CRH}$ stimulation) for differential diagnosis of ACTH dependent causes of SH; whole-body CT was performed when a possible ectopic source of ACTH hypersecretion was suspected (2).

All subjects gave their informed consent and local ethical committees approved the study in accordance with the Helsinki Declaration II.

\section{Methods}

On the day of admission all individuals had a heparinlock catheter inserted to avoid stress-related hypopituitary-adrenal-axis activation due to venipuncture; all biochemical determinations were started the day after admission. Serum cortisol (normal values $5-25 \mu \mathrm{g} / \mathrm{dl}$; $138.0-690.0 \mathrm{nmol} / \mathrm{l}$ ) and UFC (normal values $8-60 \mu \mathrm{g} / 24 \mathrm{~h} ; 22.1-165.6 \mathrm{nmol} / 24 \mathrm{~h}$ ) levels (after dichloromethane extraction) were determined immunofluorimetrically by TDX-FLX Abbott Diagnostika kits (Wiesbaden-Delkenheim, Germany). Serum ACTH (normal values $10-50 \mathrm{pg} / \mathrm{ml} ; 2.2-11 \mathrm{pmol} / \mathrm{l}$ ) levels (mean from three determinations at 20-min intervals) were measured by immunoradiometric assay (BRAHMS Diagnostica, Berlin, Germany). In all subjects F24 and UFC levels were measured twice and reported as means from the two determinations.

At San Giuseppe-Fatebenefratelli Hospital CT imaging was performed employing a Tomoscan AVE1 spiral CT scanner (Philips Medical Systems; Cleveland, $\mathrm{OH}$, USA) and NMR imaging used a 1.5 Te NMR NTIntera with software release 8 (Philips Medical Systems). At Casa Sollievo della Sofferenza Scientific Institute CT imaging was performed using Pro Speed 


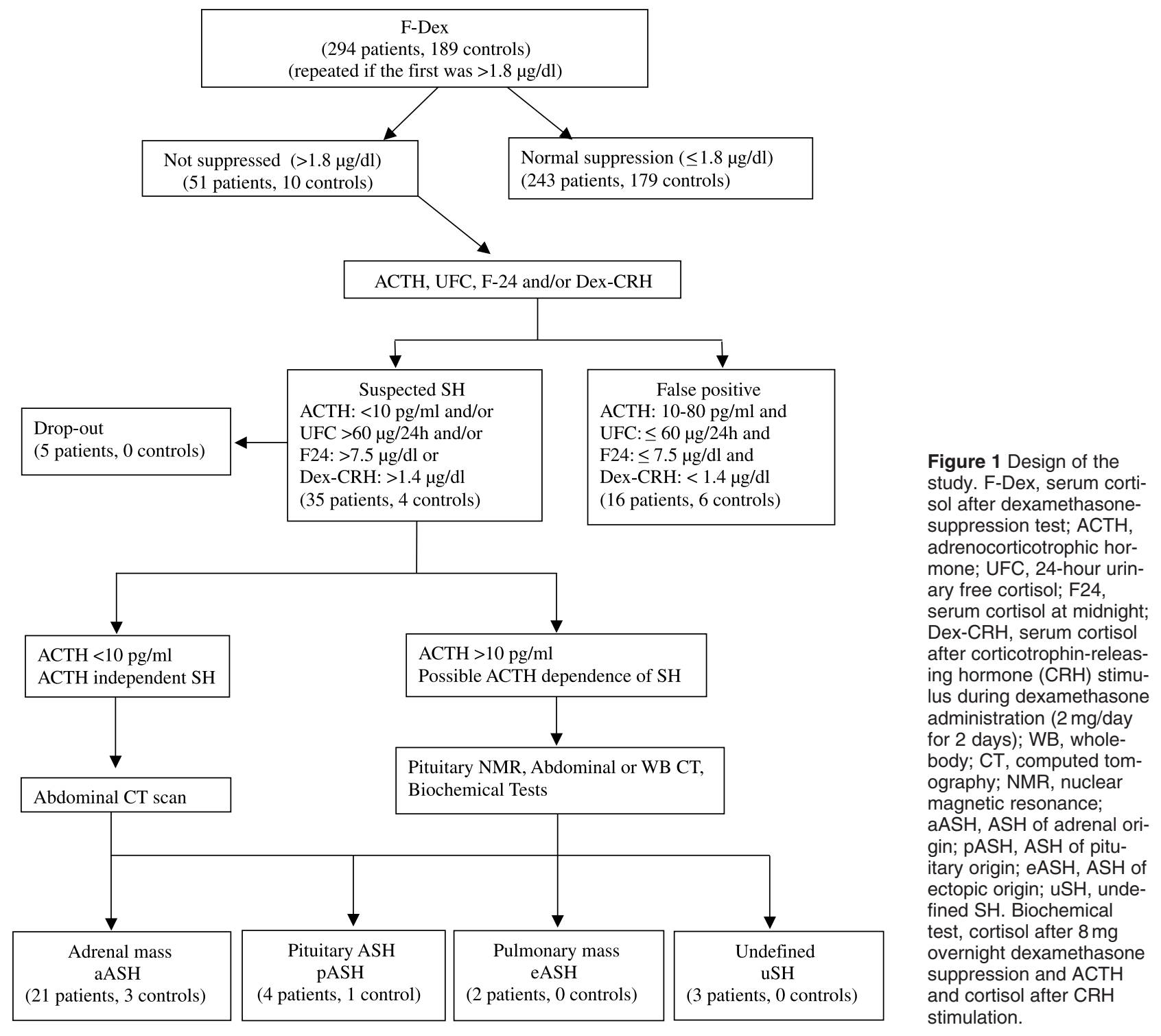

Sx power spiral CT scanner (General Electric Company, Milwaukee, WI, USA) and NMR imaging used a 1.5 Te NMR Sigma Advantage (General Electric Company). At Istituto Policlinico San Donato CT imaging was performed with a Pro Speed Sx Power CT scanner and NMR imaging employed a 1.5 Te NMR Sonata Maestro Class (Siemens, Medical Solutions USA Inc., Malvern, PA, USA). For all the CT scanners employed the thickness of slices was $5 \mathrm{~mm}$ and the resolution $2 \mathrm{~mm}$. For all NMR devices the thickness of the slices was $3 \mathrm{~mm}$ and the resolution $2 \mathrm{~mm}$. In each center the radiologist was not permitted to see to the biochemical data when performing CT and NMR imaging.

\section{Statistical analysis}

Statistical analysis was performed with SPSS version 12.0 (SPSS, Chicago, IL, USA). The results are expressed as means \pm S.D. or medians \pm range for variables that were not normally distributed. Comparison between continuous variables was performed using unpaired t-test or Mann-Whitney U test as appropriate. Categorical variables were compared by $\chi^{2}$ test. In the whole sample, logistic regression analyses were used to assess the extent of which ASH was associated with diabetes, after adjusting for possible confounders such as age, gender, BMI, hypertension, and cause of hospitalization. Similarly, logistic regression analyses was used to assess the extent to which the coexistence of hypertension, dyslipidaemia and the need for insulin treatment was associated with ASH among diabetic patients, after adjusting for possible confounders such as age, gender, BMI and age at diabetes diagnosis. Probability values of less than 0.05 were considered significant. 


\section{Results}

The clinical characteristics of diabetic and non-diabetic individuals who completed the study (see below) are compared in Table 1. As compared with non-diabetic controls, diabetic patients were more frequently affected by hypertension $(50.8$ and $63.7 \%$ respectively; $\left.\chi^{2}=7.8 ; P=0.004\right)$.

The complete diagnostic protocol for detecting and ascertaining $\mathrm{SH}$ is shown in Fig. 1. Fifty-one diabetic patients $(17.3 \%)$ and 10 non-diabetic controls (5.3\%) had two consecutive F-Dex values above $1.8 \mu \mathrm{g} / \mathrm{dl}$ $(50.0 \mathrm{nmol} / \mathrm{l})$; of these, 16 diabetic patients $(5.4 \%)$ and 6 non-diabetic controls (3.1\%) did not show, besides F-Dex, other biochemical abnormalities of the pituitary-adrenal axis, and were therefore considered as false-positive results. Five diabetic patients (1.7\%) with a suspected SH, as evidenced by biochemical results, refused to undergo morphological procedures and dropped out the study. The proportion of ASH was significantly higher in diabetic patients $(n=27)$ than in non-diabetic controls $(n=4 ; 9.4$ versus $2.1 \%$ respectively; $\chi^{2}=10.0 ; P=0.002$ ). Logistic regression analysis showed that ASH was significantly associated with T2D (adjusted odds ratio, 4.8; 95\% confidence interval, 1.6-14.1; $P=0.004)$; this was also the case when other possible confounders including age, gender, BMI, hypertension and cause of hospitalization were added to the model. Overall, in our population of inpatients the proportion of T2D that was statistically attributable to ASH was approx. $7 \%$.

Hormonal and imaging data and subsequent ascertainment of SH in diabetic individuals are given in Table 2. An adrenal expansive lesion was found in 21 patients (patients 1-21, adrenal ASH patients, Table 2); in 16 adrenal ASH patients ACTH levels were lower than $10 \mathrm{pg} / \mathrm{ml}$, and in the remaining five the level was between 10 and $20 \mathrm{pg} / \mathrm{ml}$. Patients $1-11,13-15$ and 17-18 (Table 2), with ACTH levels lower than $10 \mathrm{pg} / \mathrm{ml}$, might be also defined as affected by pre-toxic adrenal adenomas. Of the nine SH patients with ACTH levels higher than $20 \mathrm{pg} / \mathrm{ml}$ ( $4.4 \mathrm{pmol} / \mathrm{l})$, NMR imaging showed a well-defined pituitary lesion in three of them (patients 22-24 in Table 2 ), an empty sella in one patient (no. 25; Table 2) and no alterations in five additional patients (nos 26-30; Table 2). Biochemical investigations by $8 \mathrm{mg}$ overnight dexamethasone-suppression test and ACTH and cortisol levels after CRH stimulation (data not shown) and negative imaging studies by whole-body CT were consistent with ACTH hypersecretion of pituitary origin in diabetic patients 22-25 (pituitary ASH patients; Table 2); in contrast, $\mathrm{SH}$ of ectopic origin was suggested in diabetic subjects 26 and 27 (ectopic ASH patients, Table 2), who turned out to suffer from a pulmonary expansive lesion. In three diabetic subjects (nos 28-30) the source of SH remained unclear (undefined SH; Table 2).

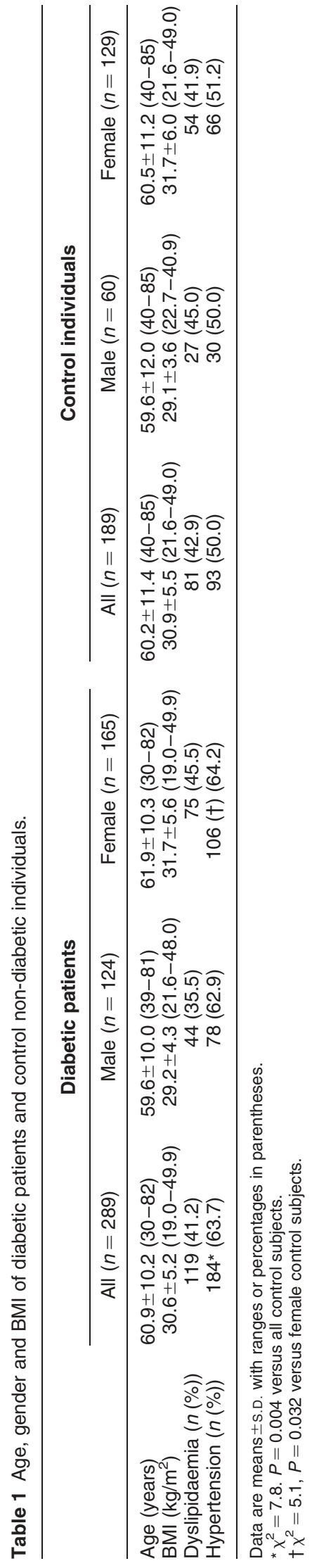


Table 2 Biochemical and imaging date of diabetic patients with SH.

\begin{tabular}{|c|c|c|c|c|c|c|c|}
\hline Patient & F-Dex $(\mu \mathrm{g} / \mathrm{dl})$ & ACTH (pg/ml) & UFC $(\mu g / 24 h)$ & F-24 ( $\mu \mathrm{g} / \mathrm{dl})$ & Dex-CRH $(\mu \mathrm{g} / \mathrm{dl})$ & Imaging findings & Diagnosis \\
\hline 1 & 2.2 & 10.0 & 31.4 & 8.0 & & $2.5 \mathrm{~cm}$, adrenal & aASH \\
\hline 2 & 3.2 & 8.2 & 21.8 & & 2.7 & $3.8 \mathrm{~cm}$, adrenal & aASH \\
\hline 3 & 1.9 & 5.0 & 20.0 & 8.7 & & $1.8 \mathrm{~cm}$, adrenal & aASH \\
\hline 4 & 9.0 & 5.0 & 12.2 & & & $2.3 \mathrm{~cm}$, adrenal & aASH \\
\hline 5 & 2.6 & 6.4 & 43.3 & 5.7 & & $1.0 \mathrm{~cm}$, adrenal & aASH \\
\hline 6 & 5.9 & 5.0 & 11.3 & 8.2 & & $1.0 \mathrm{~cm}$, adrenal & aASH \\
\hline 7 & 2.2 & 7.3 & 14.5 & & & $1.5 \mathrm{~cm}$, adrenal & aASH \\
\hline 8 & 2.8 & 6.4 & 29.6 & & 2.8 & $3.9 \mathrm{~cm}$, adrenal & aASH \\
\hline 9 & 3.4 & 7.7 & 31.8 & & 2.2 & $3.0 \mathrm{~cm}$, adrenal & aASH \\
\hline 10 & 3.6 & 7.7 & 13.7 & 13.6 & & $1.3 \mathrm{~cm}$, adrenal & aASH \\
\hline 11 & 4.1 & 5.5 & 42.6 & & & $1.0 \mathrm{~cm}$, adrenal & aASH \\
\hline 12 & 4.1 & 15.0 & 65.2 & & & $4.0 \mathrm{~cm}$, adrenal & aASH \\
\hline 13 & 2.2 & 6.4 & 43.3 & 4.4 & & $2.7 \mathrm{~cm}$, adrenal & aASH \\
\hline 14 & 2.7 & 9.1 & 19.8 & 6.9 & & $2.5 \mathrm{~cm}$, adrenal & aASH \\
\hline 15 & 2.5 & 9.1 & 25.1 & 12.3 & & $1.5 \mathrm{~cm}$, adrenal & aASH \\
\hline 16 & 2.2 & 14.1 & 76.9 & & & $1.0 \mathrm{~cm}$, adrenal & aASH \\
\hline 17 & 6.1 & 7.3 & 46.9 & 9.3 & & $3.6 \mathrm{~cm}$, adrenal & aASH \\
\hline 18 & 2.2 & 6.8 & 39.1 & 8.6 & & $1.0 \mathrm{~cm}$, adrenal & aASH \\
\hline 19 & 2.0 & 11.4 & 29.1 & & 2.4 & $1.0 \mathrm{~cm}$, adrenal & aASH \\
\hline 20 & 7.2 & 15.9 & 74.0 & & & $2.0 \mathrm{~cm}$, adrenal & aASH \\
\hline 21 & 1.9 & 18.2 & 25.0 & & 2.0 & $1.0 \mathrm{~cm}$, adrenal & aASH \\
\hline 22 & 6.2 & 26.8 & 49.2 & & 11.8 & $0.5 \mathrm{~cm}$, adrenal & pASH \\
\hline 23 & 14.4 & 66.8 & 80.0 & 27.6 & & $0.3 \mathrm{~cm}$, adrenal & pASH \\
\hline 24 & 2.1 & 19.1 & 25.9 & & 2.0 & $0.8 \mathrm{~cm}$, adrenal & pASH \\
\hline 25 & 2.0 & 28.6 & 24.3 & & 2.0 & Empty sella & pASH \\
\hline 26 & 8.4 & 30.0 & 133.5 & 13.5 & & Pulmonary & eASH \\
\hline 27 & 6.2 & 40.9 & 70.0 & 11.5 & & Pulmonary & eASH \\
\hline 28 & 4.2 & 29.5 & 21.2 & 8.9 & & Negative & uSH \\
\hline 29 & 3.1 & 23.2 & 82.0 & & & Negative & uSH \\
\hline 30 & 2.4 & 24.1 & 62.6 & & & Negative & uSH \\
\hline
\end{tabular}

ASH was diagnosed in patients with (i) F-Dex $>1.8 \mu \mathrm{g} / \mathrm{dl}$, (ii) one or more of the following: UFC $>60 \mu \mathrm{g} / 24 \mathrm{~h}$, plasma ACTH $<10 \mathrm{pg} / \mathrm{ml}, \mathrm{F} 24>7.2 \mu \mathrm{g} / \mathrm{dl}$, Dex-CRH $>1.4 \mu \mathrm{g} / \mathrm{dl}$, and (iii) in whom the source of glucocorticoid excess was identified by imaging. aASH, ASH of adrenal origin; $\mathrm{pASH}, \mathrm{ASH}$ of pituitary origin; eASH, ASH of ectopic origin; uSH, undefined subclinical hypercortisolism. Abnormal values additional to F-Dex, which led to the diagnosis of suspected SH, are bold. SI conversion factors: serum cortisol, $1 \mu \mathrm{g} / \mathrm{dl}=27.59 \mathrm{nmol} / \mathrm{l} ; \mathrm{UFC}, 1 \mu \mathrm{g} / 24 \mathrm{~h}=2.759 \mathrm{nmol} / 24 \mathrm{~h} ; \mathrm{ACTH}, 1 \mathrm{pg} / \mathrm{ml}=0.22 \mathrm{pmol} / \mathrm{l}$.

Three non-diabetic controls with ASH had adrenal lesion and one had empty sella at pituitary NMR, and both biochemical and imaging investigations consistent with ACTH hypersecretion of pituitary origin (i.e. negative whole-body $\mathrm{CT}$ ).

Clinical features of diabetic patients with $(\mathrm{SH}+)$ and without (SH - ) SH are reported in Table 3. Patients with $\mathrm{SH}$ needed insulin treatment more frequently compared with $\mathrm{SH}-$ patients (50.0 versus $32.0 \%$ respectively; $\left.\chi^{2}=3.9 ; P=0.049\right)$ and tended to be more frequently affected by hypertension and/or dyslipidaemia (Table 3). Overall, $\mathrm{SH}+$ subjects showed a higher prevalence $\left(23.3\right.$ versus $8.9 \% ; \chi^{2}=6.0$; $P=0.014$ ) of severe diabetes than $\mathrm{SH}-$ individuals, as arbitrarily defined by the coexistence of hypertension, dyslipidaemia and the need for insulin treatment.

Table 3 Clinical features of diabetic patients without or with ASH.

\begin{tabular}{lccc}
\hline & All $(n=289)$ & ASH $-(n=259)$ & ASH + $(n=30)$ \\
\hline Present age (years) & $60 \pm 10(30-80)$ & $60.5 \pm 10(30-82)$ & $64 \pm 9(41-81)$ \\
Gender (F/M) & $165 / 124$ & $148 / 111$ & $17 / 13$ \\
Age at diagnosis (years) & $51.7 \pm 10.7(31-81)$ & $51.3 \pm 10.6(31-75)$ & $54.8 \pm 11.4(34-81)$ \\
Duration of disease (years) & $8.0(0-40)$ & $8.0(0-40)$ & $10.0(0-22)$ \\
BMl (kg/m ${ }^{2}$ ) & $30.6 \pm 5.2(19.0-50.0)$ & $30.7 \pm 5.0(19.0-50.0)$ & $29.8 \pm 6.7(21.6-48.0)$ \\
$\mathrm{HbA}_{1 \mathrm{C}}$ & $9.6 \pm 2.4(5.0-15.6)$ & $9.7 \pm 2.4(5.0-15.6)$ & $9.2 \pm 2.4(5.6-14.4)$ \\
Insulin and OHA therapy (n (\%)) & $98(33.9)$ & $83(32.0)$ & $15(50.0)^{*}$ \\
Dyslipidaemia (n (\%)) & $119(41.2)$ & $104(40.2)$ & $15(50.0)$ \\
Hypertension (n (\%)) & $184(63.7)$ & $162(62.5)$ & $22(73.3)$ \\
\hline
\end{tabular}

For duration of disease data are expressed as median with range in parentheses. For the other continuous variables data are expressed as means $\pm S . \mathrm{D}$. with range in parentheses. For categorical variables (insulin and OHA therapy, dyslipidaemia, hypertension) data are absolute numbers with percentages in parentheses.

$\mathrm{HbA}_{1 \mathrm{c}}$, glycated haemoglobin; OHA, oral hypoglycaemic agents. $\mathrm{ASH}-$, patients without $\mathrm{ASH}$; $\mathrm{ASH}+$, patients with $\mathrm{ASH}$

${ }^{*} \chi^{2}=3.9, P=0.049$ versus $\mathrm{SH}-$. 
Logistic regression analysis showed that the presence of this cluster was significantly associated with SH (adjusted odds ratio, 3.8; 95\% confidence interval, $1.4-10.2 ; P=0.017)$, including when other possible confounders including age, gender, BMI, and age at diabetes diagnosis were added to the model.

Although not an aim of this study, data on the follow up of the only three patients who attempted surgical treatment for ASH are available. Notably, 3 months after surgical removal of a pituitary ACTH-secreting (by immunohistochemistry) micro-adenoma, a diabetic patient (no. 22 on Table 2) experienced amelioration of metabolic control as indicated by clinically significant reduction of both $\mathrm{HbA}_{1 \mathrm{C}}$ levels (from 11.8 to $8.1 \%$ ) and daily insulin requirement (from 50 to $24 \mathrm{UI} /$ day), Similarly, 4 months after surgical adrenal adenoma removal, two diabetic patients (nos 9 and 12 in Table 2) showed clinically significant reduction of $\mathrm{HbA}_{1 \mathrm{C}}$ levels: from 8.7 to $7.4 \%$ in patient 9 (in whom insulin therapy was also withdrawn) and from 9.4 to $5.3 \%$ in patient 12 (with no change in the dosage of the previously ongoing metformin therapy). After surgery, in all these patients the amelioration of metabolic controls occurred in the presence of stable body weight and of glucocorticoid-replacement therapy needed for hypoadrenalism.

\section{Discussion}

The definition of SH may represent, by its intrinsic nature, a semantic problem. In fact, it could be argued that in patients with biochemical alterations of the pituitary-adrenal axis, the coexistence of diseases not specifically associated with hypercortisolism (i.e. diabetes, hypertension, osteoporosis) would suggest that one should not use the term subclinical. In contrast, several groups, including ours, have been repeatedly using the term SH when biochemical alterations of pituitary-adrenal axis are not accompanied by specific signs of hypercortisolism (i.e. moon faces, striae rubrae, hypertricosis, skin atrophy, buffalo hump, proximal myopathy and acne), regardless of the coexistence of diabetes, hypertension or osteoporosis $(3,9,10,13)$.

Several observations have suggested that in T2D patients $\mathrm{SH}$ may be more frequent than previously expected $(15,22)$. However, due to the lack of data on the prevalence of $\mathrm{SH}$ in diabetic patients as compared with that in control non-diabetic individuals, the significance of these findings so far remains uncertain.

This is the first controlled study demonstrating that the prevalence of $\mathrm{ASH}$ is increased in patients with T2D. In detail, in our diabetic patients ASH was 4.8fold more frequent than in non-diabetic subjects; this association is independent of obesity and hypertension, two frequent, potentially confounding, comorbidities, which are shared by both SH and T2D. Overall, in the population studied the proportion of T2D that was statistically attributable to ASH was approx. $7 \%$. It is important to note that three diabetic patients with a biochemical diagnosis of $\mathrm{SH}$, whose ascertainment was not obtained because of the lack of a clear morphological evidence of its source (undefined SH), were not considered when calculating the $\mathrm{SH}$ prevalence in our T2D sample. The same was true for five diabetic patients who dropped out of the study after refusing morphological evaluation following biochemical diagnosis of SH (suspected SH). Thus because of our conservative approach the prevalence of $\mathrm{SH}$ in hospitalized diabetic patients might be even higher than estimated.

An additional, clinically relevant finding of our study is that diabetic patients with $\mathrm{SH}$ are affected by a more severe form of disease, as indicated by the simultaneous presence of hypertension, dyslipidaemia and the need for insulin treatment, all being well-established risk factors for diabetic complications. Our data are in line with previous data suggesting that in the course of hypercortisolism, even when subclinical, diabetic patients are characterized by poor metabolic control (10-13).

Worth noting is that in the three patients who underwent $\mathrm{SH}$ treatment by surgical removal, a clear reduction of $\mathrm{HbA}_{1 \mathrm{C}}$ values was observed, a finding that reinforces the possibility of a cause-effect relationship between $\mathrm{SH}$ and diabetes severity.

A limitation of our study is its intrinsic design (i.e. a case-control study), which allows us to show association but not causality. Nevertheless, given the recognized deleterious role of glucocorticoid excess on hyperglycaemia $(2,3,11)$, our data on both $\mathrm{SH}$ prevalence and diabetes severity suggest that $\mathrm{SH}$ is an underestimated clinical entity, which may play a significant clinical role on $\mathrm{T} 2 \mathrm{D}$.

The rate of $\mathrm{SH}$ that we found in diabetic patients and control subjects is higher than that reported previously in diabetic $(15,22)$ and general $(3)$ populations. However, available data on this topic are scarce. The study by Catargi et al. (15), employing a cut-off diagnostic value for F-Dex of $2.2 \mu \mathrm{g} / \mathrm{dl}(60 \mathrm{nmol} / \mathrm{l})$, showed a $2.0 \%$ prevalence of Cushing's disease and a $3.5 \%$ prevalence of SH in a sample of 200 diabetic subjects. Data from the study by Leibowitz et al. (22), who used a cut-off diagnostic value for F-Dex of $5.0 \mu \mathrm{g} / \mathrm{dl}$ (140 nmol/l), showed a 3.3\% prevalence of Cushing's syndrome in a series of 99 obese diabetic subjects. The apparent discrepancy with the prevalence of $\mathrm{SH}$ we found in the present study is likely to be due to the lower, and recently suggested as the most appropriate $(2,18,23)$, cut-off diagnostic value in interpreting F-Dex data (i.e. $1.8 \mu \mathrm{g} / \mathrm{dl}$ ). In addition, regarding the control individuals, because they were matched with the diabetic patients, most of them were overweight/obese and hypertensive, two clinical conditions known to be associated with glucocorticoid excess; therefore, data obtained in our control group are not comparable with those obtained in the general population $(3,24)$. 
Overall, although the absolute prevalence of $\mathrm{SH}$ we here report in hospitalized subjects may be different (i.e. higher) than that in outpatients, the relative difference we observed between diabetic and control individuals is likely to resemble that observable in the general diabetic and non-diabetic population.

As far as the origin of $\mathrm{SH}$ is concerned, the high rate $(2 / 27)$ of possible ectopic ACTH hypersecretion we found in diabetic patients is surprising. In our opinion, this finding may be, at least partially, explained by the study's setting (i.e. hospitalized patients). It must be observed that three patients with diagnosed adrenal $\mathrm{SH}$ showed unsuppressed ACTH levels and $1 \mathrm{~cm}$ adrenal mass: in these subjects the diagnosis of adrenal hypercortisolism may be at risk. On the other hand, the adrenal origin of hypercortisolism has been reported in subjects with adrenal masses of less than $2 \mathrm{~cm}$, normal ACTH and bilateral asymmetric radiocholesterol uptake at corticoadrenal scintigraphy (10).

In our opinion the high prevalence of hypercortisolism of adrenal origin may be surprising if we consider what is generally reported in patients with overt Cushing's syndrome (2); however, it must be noted that the prevalence of the different causes of $\mathrm{SH}$ is, in fact, unknown. On the other hand, it has been suggested that adrenal incidentalomas might be an unrecognized manifestation of the metabolic syndrome: the condition of hyperinsulinaemia, which characterizes T2D, may exert a stimulatory effect on the adrenal cortex, leading to the development of adrenal nodes $(11,12,25)$. This hypothesis may explain the high rate of $\mathrm{SH}$ of adrenal origin in diabetic subjects. Unfortunately, the design of this study did not allow us to look for the prevalence of non-secretory adrenal adenomas in our population, since our imaging investigations were carried out only after biochemical diagnosis of $\mathrm{SH}$ was made.

In conclusion, among hospitalized patients, $\mathrm{SH}$ is associated with T2D, especially if clinically severe. Intervention studies are needed to test a causative role for $\mathrm{SH}$ in T2D development and severity.

\section{References}

1 American Diabetes Association, Diagnosis and classification of diabetes mellitus. Diabetes Care 200427 (Suppl. 1) S5-S10.

2 Arnaldi G, Angeli A, Atkinson AB, Bertagna X, Cavagnini F, Chrousos GP, Fava GA, Findling JW, Gaillard RC, Grossmann AB, Kola B, Lacroix A, Mancini T, Mantero F, Newell-Price J, Nieman LK, Sonino N, Vance ML, Giustina A \& Boscaro M. Diagnosis and complications of Cushing's Syndrome: a consensus statement. Journal of Clinical Endocrinology \& Metabolism 2003 88 5593-5602.

3 Reincke M. Subclinical Cushing's Syndrome. Endocrinology $\mathcal{E}$ Metabolism Clinics of North America 200029 47-56.

4 Chidiac RM \& Aron DC. Incidentalomas. A disease of modern technology. Endocrinology \& Metabolism Clinics of North America $199726233-253$.
5 Kloos RT, Gross MD, Francis IR, Korobkin M \& Shapiro B. Incidentally discovered adrenal masses. Endocrine Reviews 1995 16 460-484.

6 Peppercorn PD, Grossman AB \& Rezneck RH. Imaging of incidentally discovered adrenal masses. Clinical Endocrinology (Oxford) 199848 379-388.

7 Libe R, Dall'Asta C, Barbetta L, Baccarelli A, Beck-Peccoz P \& Ambrosi B. Long-term follow-up study of patients with adrenal incidentalomas. European Journal of Endocrinology 2002 147 489-494.

8 Barzon L, Sonino N, Fallo F, Palù G \& Boscaro M. Prevalence and natural history of adrenal incidentalomas. European Journal of Endocrinology $2003149273-285$.

9 Terzolo M, Alì A, Osella G, Cesario F, Paccotti P \& Angeli A. Subclinical Cushing's syndrome in adrenal incidentalomas. Clinical Endocrinology (Oxford) $1998 \mathbf{4 8} 89-97$.

10 Rossi R, Tauchmanovà L, Luciano A, Di Martino M, Battista C, Del Viscovo L, Nuzzo V \& Lombardi G. Subclinical Cushing's sindrome in patients with adrenal incidentaloma: clinical and biochemical features. Journal of Clinical Endocrinology $\mathcal{E}$ Metabolism $2000851440-1448$.

11 Terzolo M, Pia A, Alì A, Osella G, Reimondo G, Bovio S, Daffara F, Procopio M, Paccotti P, Borretta G \& Angeli A. Adrenal incidentaloma: a new cause of the metabolic sindrome? Journal of Clinical Endocrinology \& Metabolism 200287 998-1003.

12 Angeli A \& Terzolo M. Editorial: adrenal incidentaloma-a modern disease with old complications. Journal of Clinical Endocrinology $\mathcal{E}$ Metabolism $2002874869-4871$.

13 Tauchmanovà L, Rossi R, Biondi B, Pulcrano M, Nuzzo V, Palmieri EA, Fazio S \& Lombardi G. Patients with subclinical Cushing's sindrome due to adrenal adenoma have increased cardiovascular risk. Journal of Clinical Endocrinology \& Metabolism $2002874872-4878$.

14 Bernini G, Moretti A, Iacconi P, Miccoli P, Nami R, Lucani B \& Salvetti A. Anthropometric, haemodynamic, humoral and hormonal evaluation in patients with incidental adrenocortical adenomas before and after surgery. European Journal of Endocrinology $2003148213-219$.

15 Catargi B, Rigalleau V, Poussin A, Ronci-Chaix N, Bex V, Vergnot V, Gin H, Roger P \& Tabarin A. Occult Cushing's syndrome in type-2 diabetes. Journal of Clinical Endocrinology $\mathcal{E}$ Metabolism $2003 \mathbf{8 8} 5808-5813$.

16 Papanicolaou DA, Mullen N, Kyrou I \& Nieman LK. A single midnight serum cortisol measurement distinguishes Cushing's syndrome from pseudo-Cushing states. Journal of Clinical Endocrinology \& Metabolism 199887 4515-4521.

17 Yanovski JA, Cutler GP Jr, Chrousos GB \& Nieman LK. Corticotropin-releasing hormone stimulation following low-dose dexamethasone administration. A new test to distinguish Cushing's syndrome from pseudo-Cushing states. Journal of the American Medical Association $1993692232-2238$.

18 Raff E \& Findling W. A physiologic approach to diagnosis of the Cushing Syndrome. Annals of Internal Medicine 2003 138 980-991.

19 Tsigos C, Young RJ \& White A. Diabetic Neuropathy is associated with increased activity of the hypothalamic-pituitaryadrenal axis. Journal of Clinical Endocrinology \& Metabolism $199376554-558$.

20 Cameron OG, Thomas B, Tiongco D, Hariharan M \& Greden JF. Hypercortisolism in diabetes mellitus. Diabetes Care 1987 $10662-664$.

21 Spyer G, Hattersley AT, MacDonald IA, Amiel S \& MacLeod KM. Hypoglicaemic counter-regulation at normal blood glucose concentration in patients with well controlled type-2 diabetes. Lancet $20003561970-1974$.

22 Leibowitz G, Tsur A, Chayen SD, Salammeh M, Itamar R, Cerasi E \& Gross J. Pre-clinical Cushing's syndrome: an unexpected frequent cause of poor glycaemic control in obese diabetic patients. Clinical Endocrinology (Oxford) 1996 $44717-722$. 
23 Findling JW \& Raff H. Diagnosis and differential diagnosis of Cushing's syndrome. Endocrinology \& Metabolism Clinics of North America $200130729-747$.

24 Ness-Abramov R, Nabriski D, Apovian CM, Niven M, Weiss E, Shapiro MS \& Shenkman L. Overnight dexamethasone suppression test: a reliable screen Cushing's syndrome in the obese. Obesity Research $2002101217-1221$.
25 Reincke M, Fassnacht M, Vath S, Mora P \& Allolio B. Adrenal incidentalomas: a manifestation of the metabolic syndrome? Endocrine Research $199622757-761$.

Received 21 June 2005

Accepted 9 September 2005 